\title{
Assessing the Effect of Vitamin D Replacement on Basal Cell Carcinoma Occurrence and Recurrence Rates in Patients with Vitamin D Deficiency
}

\author{
Bilsev Ince ${ }^{1} \cdot$ Mehmet Emin Cem Yildirim $^{1}$ (D) $\cdot$ Mehmet Dadaci $^{1}$ \\ Received: 14 April 2019 / Accepted: 13 June 2019 / Published online: 28 June 2019 \\ (C) Springer Science+Business Media, LLC, part of Springer Nature 2019
}

\begin{abstract}
The study aimed to determine whether $25-\mathrm{OH}$ vitamin $\mathrm{D}_{3}$ deficiency is present in patients with diagnosed $\mathrm{BCC}$, and the effect of vitamin $\mathrm{D}$ replacement on the rates of $\mathrm{BCC}$ recurrence in patients with $25-\mathrm{OH}$ vitamin $\mathrm{D}_{3}$ deficiency. In this prospective study, between 2012 and 2017, in the first stage, 25-OH vitamin $\mathrm{D}_{3}$ levels of all patients diagnosed with BCC between 2012 and 2013 were evaluated. In the second stage between 2014 and 2015, we evaluated the 25-OH vitamin $\mathrm{D}_{3}$ level of patients who had 25$\mathrm{OH}$ vitamin $\mathrm{D}_{3}$ level $<25 \mathrm{ng} / \mathrm{mL}$. All the patients included in the second stage had BCC recurrence. In the third stage, the patients who were diagnosed 25-OH vitamin $\mathrm{D}_{3}$ deficiency with $\mathrm{BCC}$, between 2015 and 2017, were studied. The mean 25-OH vitamin $\mathrm{D}_{3}$ level of the patients in the second stage was $10.12 \mathrm{ng} / \mathrm{mL}$. Recurrence was observed in $9.64 \%$ of the patients in the second stage. The mean level of serum $25-\mathrm{OH}$ vitamin $\mathrm{D}_{3}$ in the third stage was $40.1 \mathrm{ng} / \mathrm{mL}$, and $3.49 \%$ of these patients presented with recurrence. In all the patients as the initial diagnosis and following the $25-\mathrm{OH}$ vitamin $\mathrm{D}_{3}$ level in all the patients with $\mathrm{BCC}$ recurrence, maintaining 25-OH vitamin $\mathrm{D}_{3}$ levels above $25 \mathrm{ng} / \mathrm{mL}$ can significantly reduce the recurrence rate.
\end{abstract}

Keywords Basal cell carcinoma $\cdot$ Vitamin D $\cdot$ Skin cancers $\cdot$ Vitamin D deficiency

\section{Introduction}

The ozone layer has been getting thinner due to the use of chlorofluorocarbon (CFC) and hydrochlorofluorocarbon

Synopsis We aimed to determine whether vitamin D deficiency is present in patients diagnosed with $\mathrm{BCC}$ and the effect of vitamin $\mathrm{D}$ replacement on the rates of $\mathrm{BCC}$ recurrence in patients with vitamin D deficiency. In this study we determined a relation between low serum vitamin D level and both primary BCC and recurrent BCC. In all the patients as the initial diagnosis and follow-up of vitamin $\mathrm{D}$ level in all the patients with BCC recurrence maintaining vitamin D levels above 25 $\mathrm{ng} / \mathrm{mL}$ can significantly reduce the recurrence rate

Mehmet Emin Cem Yildirim

dr.cem_yildirim@hotmail.com

Bilsev Ince

bilsevince@yahoo.com

Mehmet Dadaci

mdadaci@gmail.com

1 Department of Plastic \& Reconstructive and Aesthetic Surgery, Meram Faculty of Medicine, Necmettin Erbakan University, 42080, Meram, Konya, Turkey
(HCFC). As a result, the amount of ultraviolet rays reaching earth has increased, thus affecting the incidence of nonmelanoma skin cancers (NMSCs). The incidence of basal cell carcinoma (BCC), the most common subtype of NMSC, increases $10 \%$ annually [1]. Conversely, sunlight, one of the major risk factors for these cancers, is also the main source of synthesis of 25-hydroxyvitamin $\mathrm{D}_{3}\left(25-\mathrm{OH} \mathrm{D}_{3}\right)$, which provides essential functions for the human body. Vitamin D has pleiotropic effects such as cell growth, differentiation, apoptosis, and regulation of tumor-immune system through its cancer-associated vitamin D receptor (VDR) [2, 3]. Furthermore, vitamin $\mathrm{D}$ has a protective role against colon, breast, and prostate cancers [4].

Ultraviolet (UV) radiation has opposing effects on BCC carcinogenesis, a stimulatory effect via mutagenesis, and an inhibitory effect via production of Hedgehog-inhibiting vitamin D3; thus, vitamin $\mathrm{D}_{3}$ could inhibit $\mathrm{BCC}$ carcinogenesis [5]. In other studies, it was mentioned that high vitamin $\mathrm{D}_{3}$ level reduces the risk of NMSC [6,7]. However, we could not find any study investigating the frequency of $\mathrm{BCC}$ recurrence in patients with deficiency and patients receiving vitamin $\mathrm{D}_{3}$ replacement treatment. 
This study aimed to determine whether $25-\mathrm{OH}$ vitamin $\mathrm{D}_{3}$ deficiency is present in patients with diagnosed $\mathrm{BCC}$ and to assess the effect of vitamin $D_{3}$ replacement on the rates of $\mathrm{BCC}$ recurrence in patients with vitamin $\mathrm{D}$ deficiency.

\section{Patients and Methods}

In this prospective study, between January 2012 and January 2017, we included patients who were admitted with skin lesions and diagnosed with BCC. We excluded patients diagnosed with $\mathrm{BCC}$ in the pathology report but having a surgical margin of $<0.5 \mathrm{~cm}$, gastrointestinal absorption problems, severe hypertension, parathyroid nodules, liver or kidney disease, or multiple skin lesions as well as those who did not come to the routine controls and did not use sunscreen protection. Furthermore, patients with BCC in dangerous areas, such as the nose or lower eyelid, wherein facial esthetic could be severely damaged, were excluded. Additionally, patients who followed a strict vegan diet were excluded, because most of the natural sources of vitamin D are animal-based, including fish, fish oils, egg yolks, fortified milk, and beef liver. The Necmettin Erbakan University, Meram Faculty of Medicine Clinical Research Ethics Committee, approved the study. Written informed consent and verbal approval were obtained from the patients. A single surgeon performed all procedures. All Serum 25-OH vitamin D3 levels have been investigated on the Agilent 1100 using Chromsystems' high-performance liquid chromatography kit.

The study was planned in three stages. In the first stage, the $25-\mathrm{OH}$ vitamin $\mathrm{D}_{3}$ levels of all patients diagnosed with $\mathrm{BCC}$ between January 2012 and December 2013 were evaluated. We investigated whether there was a correlation between $\mathrm{BCC}$ and $25-\mathrm{OH}$ vitamin $\mathrm{D}_{3}$ deficiency. In the second stage, between January 2014 and January 2015, we evaluated the $25-\mathrm{OH}$ vitamin $\mathrm{D}_{3}$ levels of patients who had 25-OH vitamin $\mathrm{D}_{3}$ levels $<25 \mathrm{ng} / \mathrm{mL}$. The surgical margin of the pathology material examined after primary surgery was $0.5 \mathrm{~cm}$ negative. All patients included in the second stage had BCC recurrence. Then, we investigated whether there was a correlation between $\mathrm{BCC}$ recurrence and 25-OH vitamin $\mathrm{D}_{3}$ deficiency or not. In the third stage, $50,000 \mathrm{IU}$ of oral vitamin $\mathrm{D}_{3}$ was given per week for 6 weeks as a loading dose, totaling 300,000 IU, to patients who were diagnosed with BCC between February 2015 and January 2017 and who had a negative surgical margin of $>0.5 \mathrm{~cm}$. Twenty days after the last dose, we checked the serum $25-\mathrm{OH}$ vitamin $\mathrm{D}_{3}$ level. This level ranging 25-100 $\mathrm{ng} / \mathrm{mL}$ was considered normal in the posttreatment controls. For those having serum $25-\mathrm{OH}$ vitamin $\mathrm{D}_{3}$ levels $<25 \mathrm{ng} / \mathrm{mL}$, 800 -IU oral treatment was continued as a daily maintenance dose following the loading dose. Patients in whom the serum 25-OH vitamin $\mathrm{D}_{3}$ levels did not increase following replacement therapy were excluded from the study. Patients with $\mathrm{BCC}$ who underwent vitamin $\mathrm{D}_{3}$ replacement treatment were followed up by regular controls.

While recording patients' medical histories, patients were asked about their ages, professions, religion, whether they took a summer vacation or not, and the frequency of sunbathing. In addition, the number of many female patients wearing headscarves because of their religious beliefs was also recorded in addition to the places in which patients lived, which were marked on Google maps.

Additionally, in the literature, there is knowledge to compare between different locations and equivalent systems to be used, and global irradiance should be measured, which is defined as solar irradiance on the horizontal plane [8]. Thus, we evaluated the global horizontal irradiation (GHI) of the location data from the Global Solar Atlas (Fig. 1).
Fig. 1 The mean values of the global horizontal irradiation (GHI)
The Mean Values of the Global Horizontal Irradiation

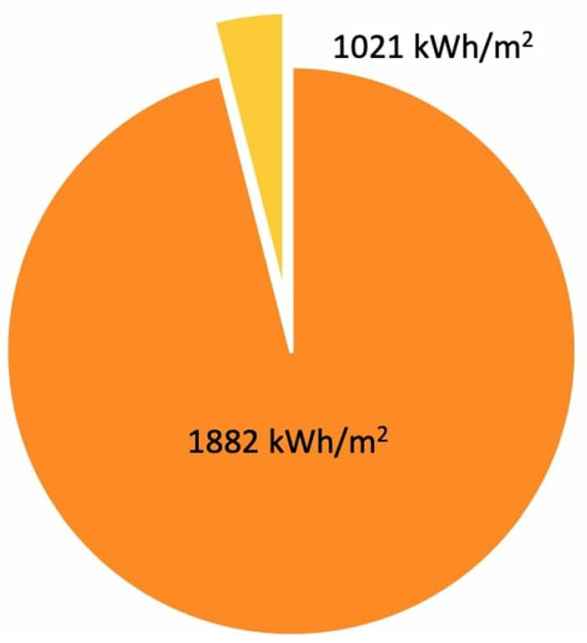

$=96 \%$ of the patients

$=4 \%$ of the patients 
Recurrence rates in these patients were compared with the recurrence rates in patients who were diagnosed with $\mathrm{BCC}$ between January 2012 and December 2013 and who did not receive vitamin $\mathrm{D}_{3}$ replacement treatment (first-stage patients). All surgical procedures were performed under local anesthesia, and a single pathologist reevaluated all the pathological preparations. At the second pathologic examination, patients with $<0.5-\mathrm{cm}$ surgical margins were excluded from the study. All patients were advised to use sun protection cream, avoid sun exposure, and attend the monthly controls.

\section{Statistical Evaluation}

Results were analyzed with SPSS 24.0 (IBM, Armonk, NY, USA). The $\chi^{2}$ test was used to evaluate the relationship between dependent variables and independent variables. The level of significance was set at $P<0.05$.

\section{Results}

A total of 496 patients were included in the study, 239 (141 male, 93 female) in the first stage, 114 (60 male, 54 female) in the second stage, and 143 (84 male, 59 female) in the third stage. The mean age of the patients was 69 years, and the mean follow-up period was 32 (range, 24-36) months. In the first stage, $88 \%$ of the patients had skin lesions in the head and neck, $6 \%$ in the upper extremities, $2 \%$ in the trunk, and $4 \%$ in the lower extremities. In the second stage, $79 \%$ of the patients had skin lesions in the head and neck, $14 \%$ in the extremities, and $7 \%$ in the trunk. In the third stage, $97.4 \%$ of the patients had the skin lesion in the head and neck and $2.6 \%$ in the extremities (Table 1).

During the initial diagnosis, the mean size of the lesions was $2.1 \times 1.6 \times 0.8 \mathrm{~cm}$. In the second stage, the mean size of the lesions was $1.9 \times 1.4 \times 0.7$, and in the third stage, the mean size was $2.3 \times 1.5 \times 0.8$.

From the patients' medical histories, $92 \%$ of the patients did not sunbathe during the summer, 4\% sunbathed 0-5 min/ day, 3\% sunbathed 5-10 $\mathrm{min} /$ day, and 1\% sunbathed 10-15 min/day. During the summer months, $89 \%$ did not take a holiday, $6 \%$ went on vacation 2-5 days/year, $4 \%$ went 5-7 days/year, and 1\% went 7-10 days/year. Eighty-four percent of female patients were veiled because of their Islamic beliefs. In total, $91 \%$ of the patients were Muslim, $7 \%$ did not declare their religion, and $2 \%$ were Christians. Eighty-one percent of the patients were working in low-income professional groups (earning < $1000 \mathrm{USD} / \mathrm{month}$ ). Recurrence was observed in $8.7 \%$ of the veiled female patients in the second stage, in $2 \%$ of the veiled female patients in the third stage.

Ninety-six percent of the patients were living in high-solar areas according to the solar heat map (Fig. 1). The mean value of the global horizontal irradiation of the patients where live is $1894 \mathrm{kWh} / \mathrm{m}^{2}$ (min. 1702-max. $2018 \mathrm{kWh} / \mathrm{m}^{2}$ ) per year.

The mean serum $25-\mathrm{OH}$ vitamin $\mathrm{D}_{3}$ level of the patients who were diagnosed with $\mathrm{BCC}$ in the first stage was 12.2 (range, 7.4-34.4; male, 12.4; female, 11.9) ng/mL. The mean $25-\mathrm{OH}$ vitamin $\mathrm{D}_{3}$ level of the patients with $\mathrm{BCC}$ recurrence in the second stage was 10.1 (range, 4.1-23.8; male, 10.2; female, 10.1) ng/mL. Recurrence was observed in $9.64 \%$ (male, $10 \%$; female, 9.26 ) of the patients in the second stage, and skin lesions were found in the head and neck in eight patients, in the upper extremities in one patient, in the upper back in one patient, and in the lower extremities in one patient. The mean serum $25-\mathrm{OH}$ vitamin $\mathrm{D}_{3}$ level in the third stage was 11.8 (range, 5.4-20.1; male, 11.7; female, 12) ng/mL. The mean serum $25-\mathrm{OH}$ vitamin $\mathrm{D}_{3}$ level after replacement therapy was 40.1 (range, 28.965.2; male, 42.3; female, 37 ) $\mathrm{ng} / \mathrm{mL}$, and $3.49 \%$ (male, $3.57 \%$; female, $3.38 \%$ ) of these patients presented with recurrence (Table 1). The recurrent lesions were found in the head and neck in five patients. Statistically significant relationships were determined between $25-\mathrm{OH}$ vitamin $\mathrm{D}_{3}$ deficiency and $\mathrm{BCC}$ frequency at the initial diagnosis and between $25-\mathrm{OH}$ vitamin $\mathrm{D}_{3}$ deficiency and $\mathrm{BCC}$ recurrence $(P<0.05)$. Recurrence rates in patients in the second stage were statistically higher than those in patients in the third stage $(P<0.05)$. There were no statistically significant differences on 25-OH vitamin D3 levels and recurrence rates in the second and third stages between male and female patients in all groups.

Table 1 The results in all stages

\begin{tabular}{llll}
\hline & 1st stage & 2nd stage & 3rd stage \\
\hline Mean age (year) & 68 & 71 & 70 \\
Sex & $141 \mathrm{M}, 93 \mathrm{~F}$ & $60 \mathrm{M}, 54 \mathrm{~F}$ & $84 \mathrm{M}, 59 \mathrm{~F}$ \\
Localization & $88 \%$ H.N., 10\% E., 2\% T. & $79 \%$ H.N., 14\% E., 7\% T. & $97.4 \%$ H.N., 2.6\% E. \\
Serum vitamin $\mathrm{D}_{3}(\mathrm{ng} / \mathrm{mL})$ & 12.23 & 10.12 & $11.81 \rightarrow 40.1^{\mathrm{a}}$ \\
Recurrence $(\%)$ & - & 9.64 & 3.49 \\
\hline
\end{tabular}

$B . B$., head-neck; $E$., extremity; $T$., trunk; $F$., female; $M$., male

${ }^{\text {a }}$ Serum vitamin $\mathrm{D}_{3}$ level after the replacement therapy 


\section{Discussion}

Skin is the only organ which is known to produce every component involved in the vitamin $\mathrm{D}_{3}$ production pathway in response to ultraviolet B (UVB, 290-320 nm) exposure [9]. As a result of the interaction of 7-dehydrocholesterol with UV, vitamin $\mathrm{D}_{3}$ is formed, and then, it is converted to 25hydroxyvitamin $\mathrm{D}_{3}$ by hydroxylation reaction in the liver. In the kidneys, 1-alpha, 25-dihydroxyvitamin $\mathrm{D}_{3}$, which is the metabolically active form, is formed [10]. Although this metabolic process occurs in the liver and kidneys, animal studies have shown that the hydroxylases in the epidermis of skin can also actively transform vitamin D3 to 25-hydroxyvitamin $\mathrm{D}_{3}$ without the involvement of the liver [11]. VDR, an intracellular receptor and transcription factor, belongs to a family of proteins that includes some steroid hormone receptors, retinoids, isoprenoids, eicosanoids, and cholesterol metabolites [12]. This receptor is present in $>60$ cell types in the human body, and when the activity of this receptor is abnormal, even if the vitamin D level is normal, the vitamin may not act correctly [13]. Activated vitamin D functions with the genomic and non-genomic pathways. The genomic pathway results in the activation of vitamin D response element, which affects over 900 gene expressions [14], whereas the nongenomic pathway is responsible for the intracrine effects of the activated vitamin D [15]. It has been claimed that this pathway may have a protective effect against DNA damage [16]. In patients with vitamin D deficiency or disorders of vitamin $\mathrm{D}$ metabolism, the non-genomic pathway failure may result in DNA damage and may lead to the development of NMSCs and recurrence after treatment. High-intensity UVB exposure has been reported to contribute to the development of skin cancer carcinogenesis associated with cutaneous inflammation and DNA damage $[17,18]$. Sun creams with sun protection factor absorb 95-98\% of the UVB radiation. However, sun protection creams can reduce the synthesis of activated vitamin $\mathrm{D}$ in the skin $[19,20]$. All 80 patients with recurrence and low 25-OH vitamin $\mathrm{D}_{3}$ level had been using sunscreen. All patients in this study ranged from 1 to 4 according to the Fitzpatrick classification.

Vitamin D is known to have a protective effect against some types of diseases and cancers via signaling mechanisms that include VDR. It has been claimed that the incidence of breast cancer in women with high UVB exposure is 50\% less than that in women with low UVB exposure [21]. In another study, it has been claimed that the incidence of prostate cancer in men with high UVB exposure is 50\% less than that in men with low UVB exposure [22]. Lappe et al. mentioned that vitamin $\mathrm{D}_{3}$ and calcium supplementation significantly reduce all cancer risks in postmenopausal women [23]. Although there is a relationship between vitamin D and some types of cancer in the literature, there is no study showing a significant relationship between vitamin D supplementation and the prevention treatment of NMSC in large patient populations. In a case-control study in senior men, it was proposed that NMSC development was lower in patients with high serum previtamin D metabolite than in those with low serum previtamin D metabolite [6]. Moreover, increased plasma previtamin D levels have been shown to reduce metastasis and increase survival $[16,24]$. Besides, it was claimed that vitamin $\mathrm{D}_{3}$ and $1,25 \mathrm{D}_{3}$ levels might help to determine survival prognosis and metastasis in skin cancer as well as lung, breast, and prostate cancers [25-27]. In the third stage of our study, patients who underwent vitamin $\mathrm{D}_{3}$ replacement treatment were found to have significantly lesser incidence of $\mathrm{BCC}$ recurrence than the non-replacement group. Vitamin D is primarily synthesized in summer due to higher sun exposure, and its synthesis decreases in winter when the sun exposure is lower. Although higher and lower serum levels are expected in summer and winter, respectively, it is recommended that the $25-\mathrm{OH}$ vitamin $\mathrm{D}_{3}$ level should be $>25 \mathrm{ng} / \mathrm{mL}$ even in winter when the sun exposure is lower. Therefore, we overlooked the seasonal differences in $25-\mathrm{OH}$ vitamin $\mathrm{D}_{3}$ measurements of the patients at the time of admission.

Although female patients live in areas with intense sun, they have low serum $25-\mathrm{OH}$ vitamin $\mathrm{D}_{3}$ levels. We think that the cause of these low levels was due to the veils that were worn in accordance with their religious beliefs (84\%). In men, the low serum $25-\mathrm{OH}$ vitamin $\mathrm{D}_{3}$ levels may have been due to lack of vacations and sunbathing habits in summer months since $92 \%$ of the patients did not sunbathe, and $89 \%$ did not take vacation during those months. Additionally, a large part of patients live in similar geographic region. Since $96 \%$ of the patients live in high solar areas, it may not be true to compare statistically between patients in high solar areas and the other $4 \%$ of patients.

A comparison of the recurrence rates of patients diagnosed with BCC between February 2015 and January 2017 with those of patients diagnosed with BCC between January 2012 and February 2013 can be shown as a disadvantage of our study. However, we believe it is not ethically correct not to make the necessary replacement treatment. Therefore, the control and study group consisted of patients who presented in different periods.

In this study, we demonstrated the existence of a statistically significant relationship between low serum $25-\mathrm{OH}$ vitamin $\mathrm{D}_{3}$ level and both primary $\mathrm{BCC}$ and recurrent $\mathrm{BCC}$. Furthermore, we found that vitamin $\mathrm{D}_{3}$ replacement therapy in patients with $\mathrm{BCC}$ reduced the recurrence rate. Vitamin $\mathrm{D}$ can also be taken with nutrients, but its most important source is the exposure of skin with sunlight [28]. It is known that this synthesis is mediated by UVB $(290-320 \mathrm{~nm})$ that reaches earth at its highest level around noon [28]. On the other hand, UVB is known to be a risk factor in the development of BCC, and patients are advised to avoid sunlight at noon, when the sunlight reaches vertically [6]. As a solution to this paradox, 
we think that patients with $\mathrm{BCC}$ may avoid sunlight exposure of dangerous areas, but may expose other body areas without $\mathrm{BCC}$ during daylight for 10-15 minutes. In patients who should not be in contact with sunlight, $25-\mathrm{OH}$ vitamin $\mathrm{D}_{3}$ levels should be checked regularly, and vitamin $\mathrm{D}_{3}$ replacement should be considered a solution.

\section{Conclusion}

After measuring the 25-OH vitamin $\mathrm{D}_{3}$ levels in all the patients with $\mathrm{BCC}$ recurrence, we conclude that maintaining 25$\mathrm{OH}$ vitamin $\mathrm{D}_{3}$ levels $>25 \mathrm{ng} / \mathrm{mL}$ in patients with an initial diagnosis of $\mathrm{BCC}$ can significantly reduce the recurrence rate after BCC.

Acknowledgments The authors thank Mehmet Uyar, MD, for his statistical analysis support.

Author Contributions Study conception and design: Ince. Acquisition of data: Ince, Yildirim. Analysis and interpretation of data: Ince, Dadaci

\section{Compliance with Ethical Standards}

Disclaimer The research was not sponsored by an outside organization. We (all of the authors) have agreed to allow full access to the primary data and to allow the journal to review the data if requested.

Conflict of Interest The authors declare that they have no conflict of interest.

Ethical Review Committee Statement This study conformed to the Helsinki Declaration.

\section{References}

1. Goto M, Kai Y, Arakawa S et al (2012) Analysis of 256 cases of basal cell carcinoma after either one-step or two-step surgery in a Japanese institution. J Dermatol 39(1):68-71

2. Tosetti F, Ferrari N, De Flora S et al (2002) 'Angioprevention': angiogenesis is a common and key target for cancer chemopreventive agents. FASEB J 16(1):2-14

3. Ince B, Sakarya ME, Dadaci M (2018) An assessment of the effects of serum vitamin d levels on snoring in patients who have undergone septorhinoplasty. Turk J Plast Surg 26(2):50-55

4. Giovannucci E (2009) Vitamin D and cancer incidence in the Harvard cohorts. Ann Epidemiol 19(2):84-88

5. Makarova A, Wang G, Dolorito JA, KC S, Libove E, Epstein EH Jr (2017) Vitamin $\mathrm{D}_{3}$ produced by skin exposure to UVR inhibits $m$ urine $b$ asal cell carcinoma carcinogenesis. J Invest Dermatol 137(12):2613-2619

6. Tang JY, Parimi N, Wu A et al (2010) Inverse association between serum $25(\mathrm{OH})$ vitamin D levels and non-melanoma skin cancer in elderly men. Cancer Causes Control 21:387-391

7. Park MS, Li T, Wu S et al (2016) Vitamin D intake and risk of skin cancer in US women and men. PLoS One 11(8):e0160308

8. Altmeyer P, Hoffmann K, Stücker M (eds) (1997) Skin cancer and UV radiation. Springer, Berlin
9. Webb AR (2006) Who, what, where and when- influences on cutaneous vitamin D synthesis. Prog Biophys Mol Biol 92(1):17-25

10. DeLuca HF (2004) Overview of general physiologic features and functions of vitamin D. Am J Clin Nutr 80(6 Suppl):1689S-1696S

11. Bikle DD, Nemanic MK, Gee E, Elias P (1986) 1,25Dihydroxyvitamin $\mathrm{D}_{3}$ production by human keratinocytes. Kynetic and regulation. J Clin Invest 78(2):557-566

12. Jones G, Strugnell SA, DeLuca HF (1998) Current understanding of the molecular actions of vitamin D. Physiol Rev 78(4):1193-1231

13. Walters MR (1992) Newly identified actions of the vitamin D endocrine system. Endocr Rev 13(4):719-764

14. Schuster I (2011) Cytochromes P450 are essential players in the vitamin D signaling system. Biochim Biophys Acta 1814(1):186-199

15. Norman AW, Mizwicki MT, Norman DP (2004) Steroid-hormone rapid actions, membrane receptors and a conformational ensemble model. Nat Rev Drug Discov 3:27-41

16. Deeb KK, Trump DL, Johnson CS (2007) Vitamin D signalling pathways in cancer: potential for anticancer therapeutics. Nat Rev Cancer 7(9):684-700

17. Gallagher RP, Hill GB, Bajdik CD et al (1995) Sunlight exposure, pigmentary factors, and risk of nonmelanocytic skin cancer. I. Basal cell carcinoma. Arch Dermatol 131(2):157-163

18. Strickland PT, Vitasa BC, West SK, Rosenthal FS, Emmett EA, Taylor HR (1989) Quantitative carcinogenesis in man: solar ultraviolet B dose dependence of skin cancer in Maryland watermen. J Natl Cancer Inst 81(24):1910-1913

19. Holick MF, Chen TC, Lu Z, Sauter E (2007) Vitamin D and skin physiology: a D-lightful story. J Bone Miner Res 22(Suppl 2):V28-V33

20. Ince B, Uyar I, Dadaci M (2019) Effect of Vitamin D deficiency on hypertrophic scarring. Dermatol Surg 45(2):274-279

21. Grant WB (2010) Relation between prediagnostic serum 25hydroxyvitamin $\mathrm{D}$ level and incidence of breast, colorectal, and other cancers. J Photochem Photobiol B 101(2):130-136

22. Baeke F, van Etten E, Gysemans C et al (2008) Vitamin D signaling in immune-mediated disorders: evolving insights and therapeutic opportunities. Mol Asp Med 29(6):376-387

23. Lappe JM, Travers-Gustafson D, Davies KM, Recker RR, Heaney RP (2007) Vitamin D and calcium supplementation reduces cancer risk: results of a randomized trial. Am J Clin Nutr 85(6):1586-1591

24. Godar DE, Landry RJ, Lucas AD (2009) Increased UVA exposures and decreased cutaneous Vitamin D(3) levels may be responsible for the increasing incidence of melanoma. Med Hypotheses 72(4): 434-443

25. Ramirez AM, Wongtrakool C, Welch T, Steinmeyer A, Zügel U, Roman J (2010) Vitamin D inhibition of pro-fibrotic effects of transforming growth factor beta1 in lung fibroblasts and epithelial cells. J Steroid Biochem Mol Biol 118(3):142-150

26. Shannan B, Seifert M, Boothman DA, Tilgen W, Reichrath J (2007) Clusterin over-expression modulates proapoptotic and antiproliferative effects of $1,25(\mathrm{OH}) 2 \mathrm{D} 3$ in prostate cancer cells in vitro. $\mathrm{J}$ Steroid Biochem Mol Biol 103(3-5):721-725

27. Perez-Lopez FR, Chedraui P, Haya J (2009) Review article: vitamin D acquisition and breast cancer risk. Reprod Sci 16(1):7-19

28. Ince B, Yildirim MEC, Ismayilzade M, Dadaci M (2018) Vitamin D and systemic effects of vitamin D deficiency. Selcuk Med J 2(34): 84-89

Publisher's Note Springer Nature remains neutral with regard to jurisdictional claims in published maps and institutional affiliations. 